\title{
Polymer Blend of Polycarbonate and Thermotropic Liquid Crystalline Polyester with a Long Flexible Spacer in the Main Chain
}

\author{
Boo Young SHIN and In Jae CHUNG* \\ Department of Chemical Engineering, \\ Korea Advanced Institute of Science and Technology, \\ P.O. Box 131, Cheongryang, Seoul, Korea
}

(Received February 27, 1989)

\begin{abstract}
The thermotropic liquid crystalline polyester (LCP) with a long flexible spacer in the main chain was prepared by melt polymerization. A blend of polycarbonate (PC) and LCP was prepared by melt mixing. Morphological, thermal and mechanical properties of the blend were investigated by scanning electron microscopy (SEM), differential scanning calorymetry (DSC), cross-polarizing microscope and tensile test. SEM observations proved that the interfacial adhesion between PC and LCP was good and spherical or ellipsoidal particles of LCP in the matrix were deformed to a microfibril structure under an extension flow. The ratio of the LCP domain increased with LCP content. Fibers were made by passing the blend through a capillary rheometer with varying draw ratio. The microfibrils of LCP in the blend fiber had smaller diameter as the draw ratio increased. Tensile tests showed that a fiber with $30 \mathrm{wt} \%$ LCP made at 8 draw ratio had three times the strength at the break and modulus but had much lower elongation at the break than that of PC. The mechanical properties of fibers were highly affected by the draw ratio.

KEY WORDS Thermotropic/Liquid Crystalline Polymer / Flexible Spacer

/ Polymer Blend / Interfacial Adhesion / Polycarbonate / Morphology /

Aspect Ratio /
\end{abstract}

It is well known that liquid crystalline polymers are easily oriented by a shear or an elongational flow ${ }^{1,2}$ and they have high modulus along the fiber axis. Thus they have been applied not only for the production of highmodulus/strength fibers and molded articles ${ }^{3}$ but also for the reinforcement of polymers as fillers. $^{4-8}$

Intensive research has been done on the blend of liquid crystalline polymer and isotropic polymer to improve mechanical properties after Takayanagi et al. used lyotropic liquid crystalline polymer as a reinforcement. ${ }^{4}$ It is recognized that thermotropic liquid crystalline polymers can be used as attractive reinforcing materials. ${ }^{6-9}$

\footnotetext{
* To whom all correspondence should be addressed.
}

Mechanical properties of a blend are affected by the mode of dispersion, size, shape and orientation of added material filler. But another significant mode is interfacial adhesion between two phases. In order to improve the adhesion between thermotropic liquid crystalline polymer (LCP) and matrix polymer, we introduced long flexible spacers into the main chain of LCP in our previous paper. ${ }^{10}$ The results showed that the adhesion was good and the mechanical properties could be significantly increased by the addition of LCP with high molecular weight.

In this paper, the effects of LCP with long flexible spacers in the main chain on the mechanical/thermal properties and mor- 
phology of blends were studied and it was investigated whether LCP could be used for good reinforcement of polycarbonate by increasing the molecular weight of LCP through melt polymerization. The effects of draw ratio and LCP component were also investigated.

\section{EXPERIMENTAL}

LCP with long flexible spacers in the main chain was prepared by the following reaction procedure: After the first polymerization described in the previous paper in detail, ${ }^{10}$ the temperature was maintained at $200^{\circ} \mathrm{C}$ for $2 \mathrm{~h}$, raised to $290^{\circ} \mathrm{C}$ and then kept at this temperature stirring the reactor for $1 \mathrm{~h}$ under nitrogen circumstance. The reactor was kept at the same temperature under vacuum for $20 \mathrm{~min}$ and cooled down to room temperature. The product taken by breaking the glass flask was dried in a vacuum oven at $100^{\circ} \mathrm{C}$ and powdered as fine as possible. The chemical structure of LCP is

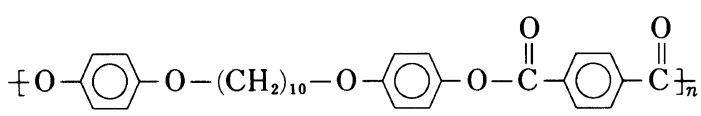

The flexible groups $\left(-\mathrm{O}-\left(\mathrm{CH}_{2}\right)_{10}-\mathrm{O}-\right)$ between rigid mesogen groups

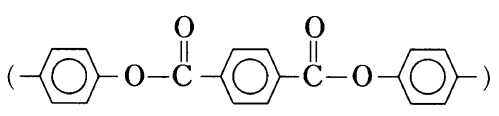

should increase the flexibility of the molecule. The LCP was characterized by using DSC (du Pont 910 Thermal Analyzer) and a crosspolarizing microscope (Carl-Zeiss model D7082 with hot stage).

Polycarbonate (General Electric Co., trade name Lexane) was chosen as the matrix polymer. Two polymers of PC and LCP were mixed using a mixing vesse ${ }^{11}$ at $295^{\circ} \mathrm{C}$ under nitrogen atmosphere and then extruded through a die of the capillary rheometer (Instron 3211 ) at a $\mathrm{L} / \mathrm{D}$ ratio of 40 at $280^{\circ} \mathrm{C}$. The extrudate of molten state was elongated by a take-up machine below the capillary die. The draw ratio was determined by measuring the reduction in fiber diameter. $\mathrm{LCP}$ content of the blend was varied over the range of $5-30 \mathrm{wt} \%$.

Tensile properties were measured at $5 \mathrm{~cm} \mathrm{~min}^{-1}$ cross-head speed using an Instron (model 4201) tensile tester with gage length $3 \mathrm{~cm}$ at room temperature. Each tensile property was the average value of 6 tests.

For the morphological investigation, fractured surfaces of samples were examined by an SEM (Hitachi model 510). To measure the aspect ratio of LCP fibril in a fiber, the fiber was etched with methylene chloride and examined by SEM. All samples were coated with gold for microscopy.

\section{RESULTS AND DISCUSSION}

\section{Thermal Behavior}

As shown in Figure 2 and Table I, the thermotropic liquid crystalline polyester had a glass transition temperature $\left(T_{\mathrm{g}}\right)$ of $183^{\circ} \mathrm{C}$, melting temperature $\left(T_{\mathrm{m}}\right)$ of $272^{\circ} \mathrm{C}$, isotropization temperature $\left(T_{\mathrm{i}}\right)$ of $327^{\circ} \mathrm{C}$ and crystallization temperature $\left(T_{\mathrm{c}}\right)$ of $245^{\circ} \mathrm{C}$. Inherent viscosity of LCP (IV of solutions in $p$ chlorophenol at a concentration of $0.2 \mathrm{~g} \mathrm{dl}^{-1}$ at $45^{\circ} \mathrm{C}$ ) was $0.79 \mathrm{dl} \mathrm{g}^{-1}$. The molecular weight of LCP used here was as high as that of Lenz et $a l{ }^{12,13}$ The texture of LCP, as shown in Figure 1 , was a typical marbled texture of nematic phase at $280^{\circ} \mathrm{C}$. ${ }^{14}$ With temperature rise the texture showed longer threads. ${ }^{12,13}$

DSC results of various blends are shown in Figure 3 and their thermal properties are listed in Table I. The $T_{\mathrm{g}}$ of polycarbonate becomes slightly higher by adding LCP because of the partial mixing of LCP and PC. The shifting of $T_{\mathrm{g}}$ of LCP was not found due to a week endothermic peak of LCP but the $T_{\mathrm{c}}$ of LCP was highly affected by PC contents. The $T_{\mathrm{c}}$ shifted from $245^{\circ} \mathrm{C}$ of pure LCP to $212^{\circ} \mathrm{C}$ of the blend with $95 \mathrm{wt} \%$ of $\mathrm{PC}$, which indicates that PC disturbs the crystallization of pure LCP in the blend. 


\section{Mechanical Properties}

The tensile properties of pure LCP and $\mathrm{PC}$ are listed in Table II. The modulus and strength at the break of pure LCP showed a interesting results. They were highly affected

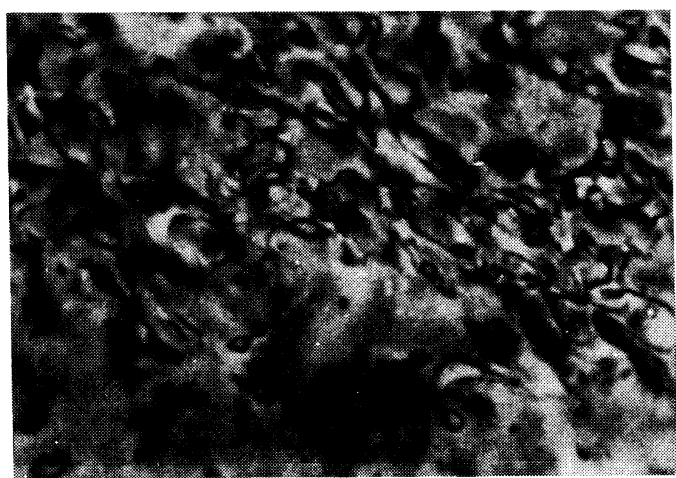

a

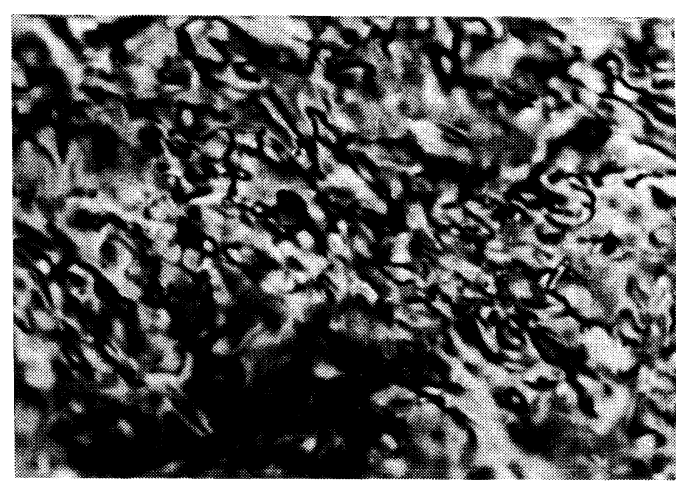

b

Figure 1. Polarized optical micrographs of LCP on heating: (a) $280^{\circ} \mathrm{C}$; (b) $290^{\circ} \mathrm{C}(320 \times)$. by the draw ratio. The strength at break increased from $59 \mathrm{MPa}$ to $514 \mathrm{MPa}$ and the modulus from $2.67 \mathrm{GPa}$ to $12.68 \mathrm{GPa}$ as the draw ratio increased from 1 to 8 . The pure LCP showed high properties such as those of commercialized thermotropic liquid crystalline polymer $\mathrm{X} 7 \mathrm{G}$ and Vectra. ${ }^{7,15}$ Unlike the pure LCP, pure PC was not affected much by the draw ratio.

Figure 4 shows the stress-strain curves for the blend of PC and LCP with various LCP contents. The modulus and strength of the blend increase with LCP contents and are listed in detail in Table II. The tensile strength at break and modulus are about 3.6 times and 3 times those of pure $\mathrm{PC}$ by adding of $30 \mathrm{wt} \%$ LCP at the draw ratio of 8 . These results indicate the possibility that LCP with long

Table I. Thermal transition of LCP/PC blends

\begin{tabular}{|c|c|c|c|c|}
\hline LCP content & $T^{\mathrm{a}}$ & $T^{\mathrm{b}}$ & $T^{\mathrm{c}}$ & $T^{\mathrm{d}}$ \\
\hline$\%$ & ${ }^{\circ} \mathrm{C}$ & ${ }^{\circ} \mathrm{C}$ & ${ }^{\circ} \mathrm{C}$ & ${ }^{\circ} \mathrm{C}$ \\
\hline 0 & - & 143 & - & - \\
\hline 5 & - & 143 & - & 212 \\
\hline 10 & - & 146 & 270 & 221 \\
\hline 20 & 一 & 147 & 272 & 228 \\
\hline 30 & - & 150 & 272 & 240 \\
\hline 100 & 183 & - & 272 & 245 \\
\hline
\end{tabular}

a Glass transition temperature of LCP in the blends.

b Glass transition temperature of PC in the blends.

c Melt temperature of LCP.

d Crystallization peak temperature of LCP.

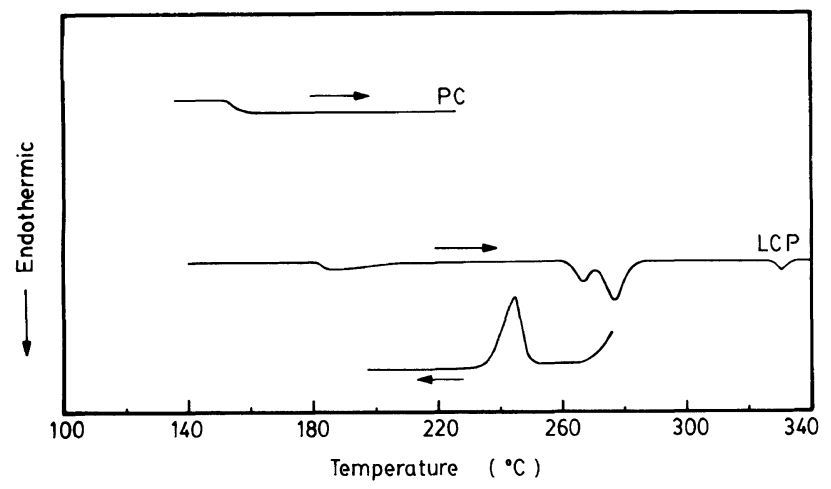

Figure 2. DSC thermograms of LCP and PC (scan rate, $10^{\circ} \mathrm{C} \mathrm{min}{ }^{-1}$ ). 


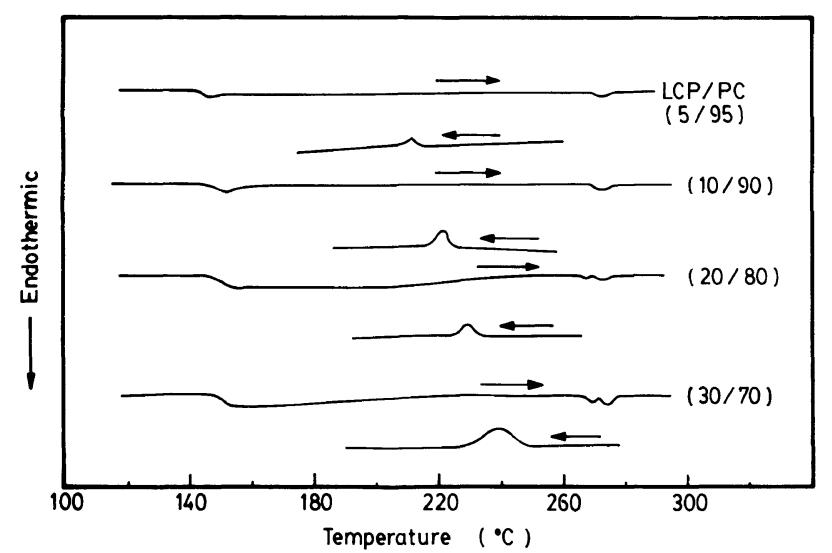

Figure 3. DSC thermograms of LCP/PC blends (scan rate, $10^{\circ} \mathrm{C} \min ^{-1}$ ).

Table II. Tensile properties of LCP/PC blend fibers

\begin{tabular}{|c|c|c|c|c|}
\hline LCP content & \multirow{2}{*}{ Draw ratio } & \multirow{2}{*}{$\frac{\text { Tensile strength }^{\mathrm{a}}}{\mathrm{MPa}}$} & \multirow{2}{*}{$\frac{\text { Elongation }^{\mathrm{b}}}{\mathrm{o} /}$} & \multirow{2}{*}{$\frac{\text { Modulus }^{\mathrm{c}}}{\mathrm{GPa}}$} \\
\hline$\%$ & & & & \\
\hline \multirow[t]{3}{*}{0} & 1 & 63 & 109.3 & 1.89 \\
\hline & 3 & 74 & 102.7 & 2.00 \\
\hline & 8 & 96 & 90.2 & 2.38 \\
\hline \multirow[t]{3}{*}{5} & 1 & 64 & 92.1 & 1.79 \\
\hline & 3 & 75 & 82.8 & 2.08 \\
\hline & 8 & 96 & 78.6 & 3.36 \\
\hline \multirow[t]{3}{*}{10} & 1 & 81 & 32.0 & 2.03 \\
\hline & 3 & 107 & 15.6 & 2.52 \\
\hline & 8 & 116 & 18.8 & 3.21 \\
\hline \multirow[t]{3}{*}{20} & 1 & 90 & 19.8 & 2.08 \\
\hline & 3 & 113 & 7.8 & 3.01 \\
\hline & 8 & 221 & 6.3 & 5.25 \\
\hline \multirow[t]{3}{*}{30} & 1 & 123 & 12.8 & 2.33 \\
\hline & 3 & 151 & 7.8 & 3.98 \\
\hline & 8 & 342 & 6.9 & 7.09 \\
\hline \multirow[t]{3}{*}{100} & 1 & 59 & 8.5 & 2.67 \\
\hline & 3 & 200 & 5.2 & 4.21 \\
\hline & 8 & 514 & 4.3 & 12.68 \\
\hline
\end{tabular}

a Ultimate tensile strength.

b Ultimate elongation.

c Initial modulus.

flexible spacers can be used for reinforcement of PC.

Figures 5 and 6 show that both the strength and modulus of the fiber made at draw ratio 3 and 1 increase linearly with LCP content, but increase sharply for the draw ratio of 8 . Table 


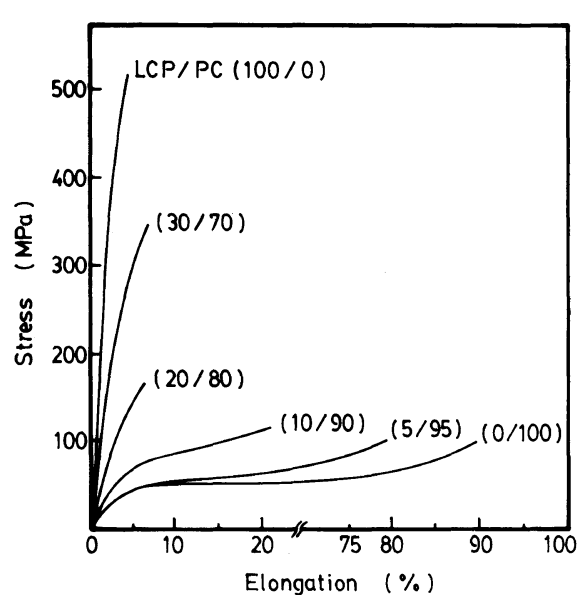

Figure 4. Stress-strain curves for fibers of a blend (draw ratio of 8 ).

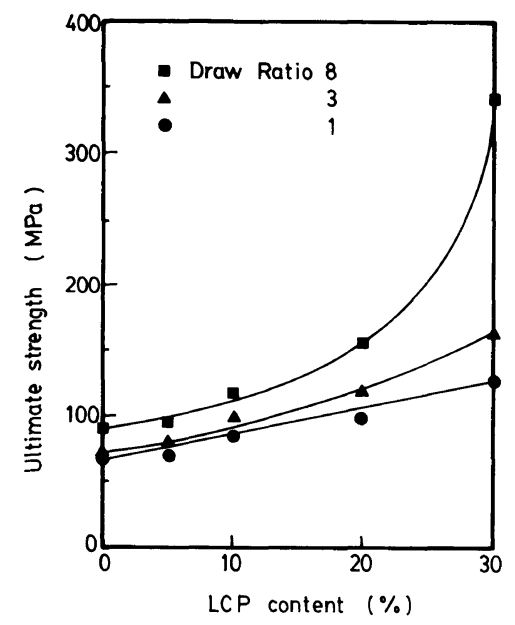

Figure 5. Effects of the draw ratio and LCP content on ultimate tensile strength of LCP/PC blend fibers.

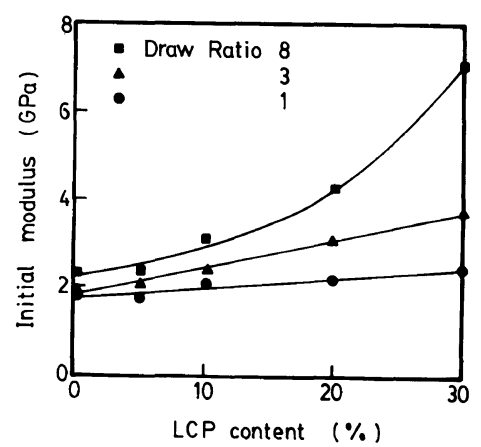

Figure 6. Effects of the draw ratio and LCP content on initial modulus of LCP/PC blend fibers.
II shows all the ultimate elongations decreasing significantly with LCP content and are affected by the draw ratio.

\section{Morphology}

The morphology of the fiber made from pure LCP is seen to consist of fibrils in Figure 7(a), (b). It shows the same structure of a liquid crystalline polymer's fiber as defined by Jaffe et al. ${ }^{15}$ and a low degrees of fibrilation. At a draw ratio of 8 , the fine fibrils are observed to be highly oriented shape in Figure 7(c), (d) as a result of the high degree of fibrilation. Morphological change with the draw ratio seems related to the mechanical properties of the pure LCP listed in Table II in the sense that high degree of fibrillation causes the high modulus.

Figure 8(a) reveals that the blend with $5 \mathrm{wt} \% \mathrm{LCP}$ for the draw ratio of 1 has a uniform dispersion of LCP spherical particles with diameters ranging from $0.2 \mu \mathrm{m}$ to $1 \mu \mathrm{m}$. Figure $8(\mathrm{~b})$ shows fine spherical particle shape in the residue extracted by methylene chloride in Figure 8(b). Tensile fractured surface for the same ratio shows that particles of LCP are deformed due to good interfacial adhesion between two polymers ${ }^{8}$ in Figure 8(c). Figure $8(\mathrm{~d})-(\mathrm{g})$ indicate that spherical particles deformed to rod-like fibrils because of the elongational flow. The aspect ratio of a LCP fibril in the matrix is considered to be about $2-10$.

The blend with $10 \mathrm{wt} \%$ of LCP shows an interesting morphological change. Figure $9(\mathrm{a})$ and (b) show a fibrillar formation of LCP particles with diameter of $0.1-1.0 \mu \mathrm{m}$ and some randomly dispersed ellipsoidal particles. The aspect ratios of these fibrils are about 2100. Baird et al. ${ }^{17}$ showed that the fibrillar formation of LCP particles occurred at $30 \mathrm{wt} \%$ of LCP for other LCP/PC blend systems. The LCP content for the fibrillar formation shifts to a lower concentration in our system than that in Baird et al.'s system. This gives a hope that thermotropic liquid crystalline polymers can be used as a reinforcement because fibrils 


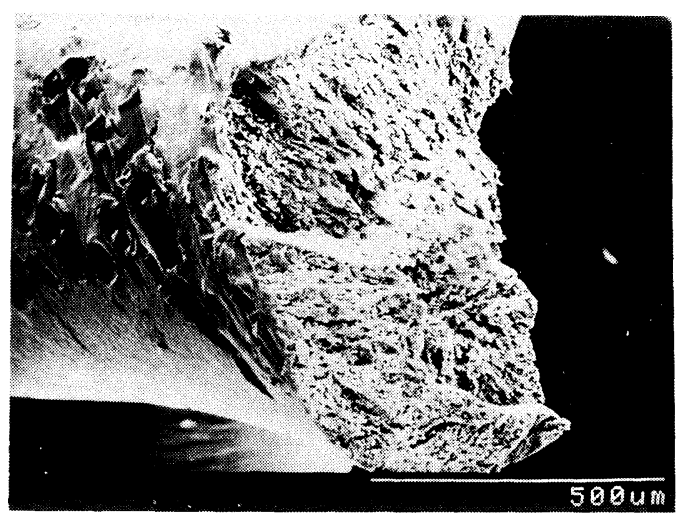

a

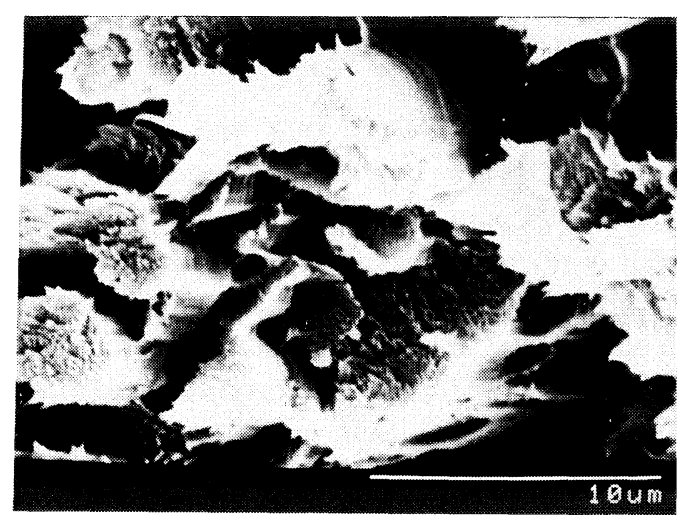

b

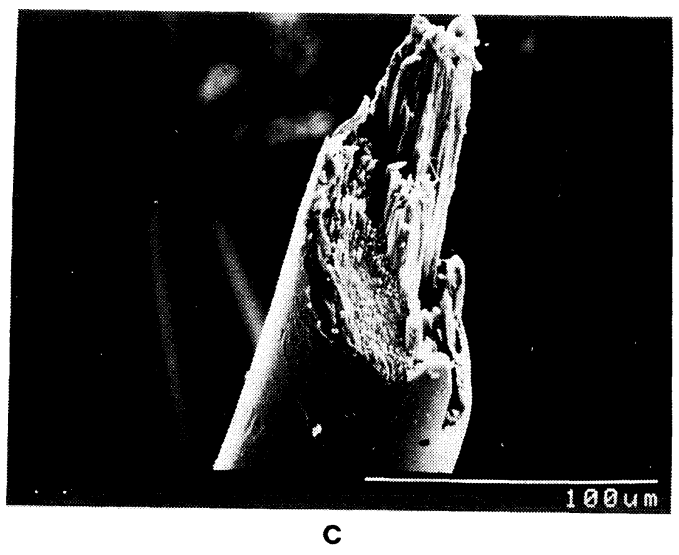

Figure 7.

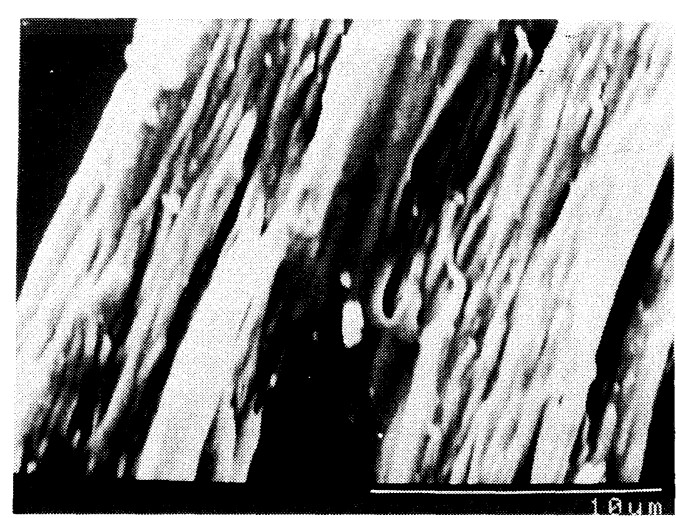

d

Figure 7. Scanning electron micrographs of tensile fractured surfaces of LCP fibers at a draw ratio of 1 (a) $100 \times$, (b) $5000 \times$, and draw ratio of 8 (c) $500 \times$, (d) $5000 \times$

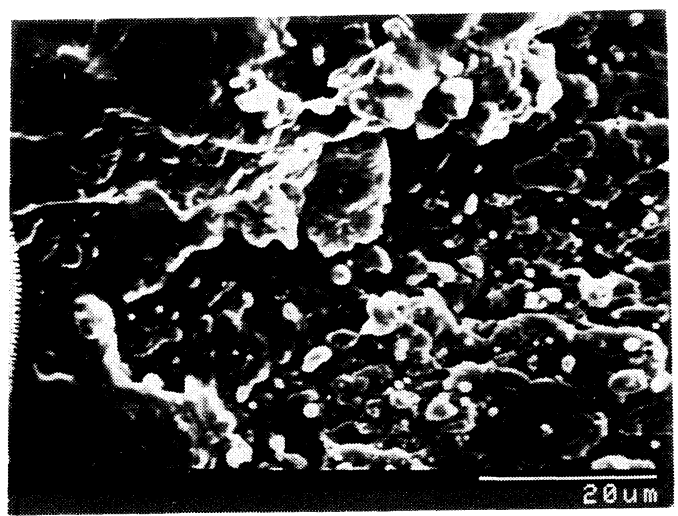

a

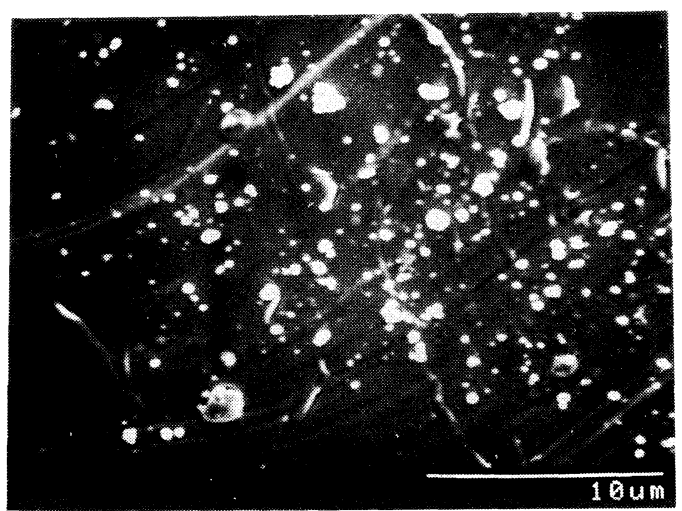

b

Figure 8.

Polymer J., Vol. 21, No. 11, 1989 


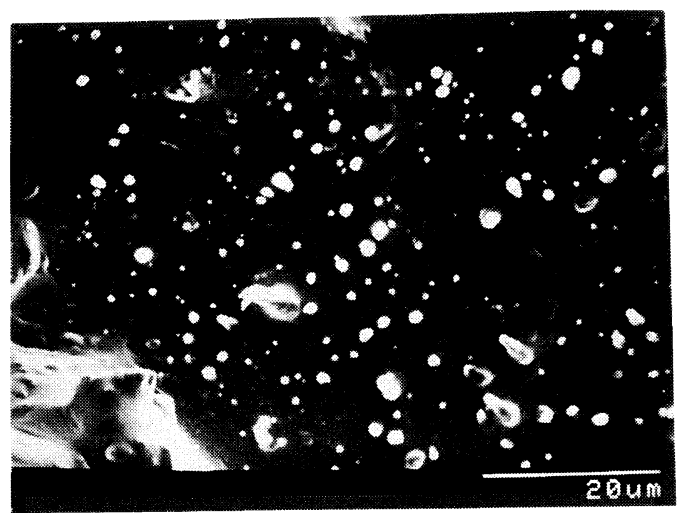

C

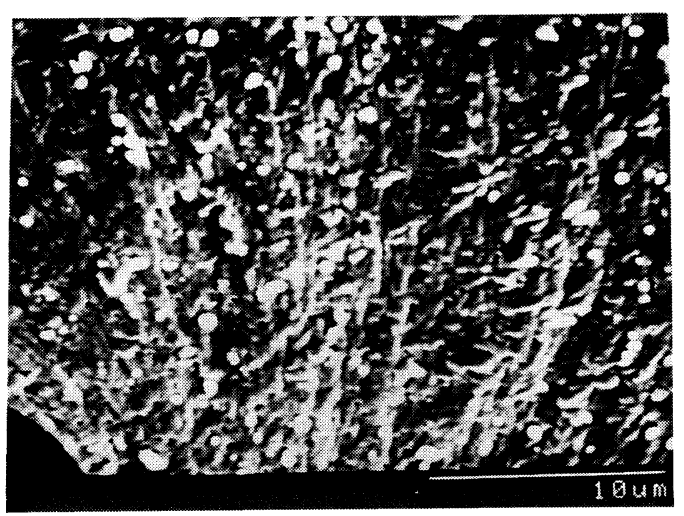

d

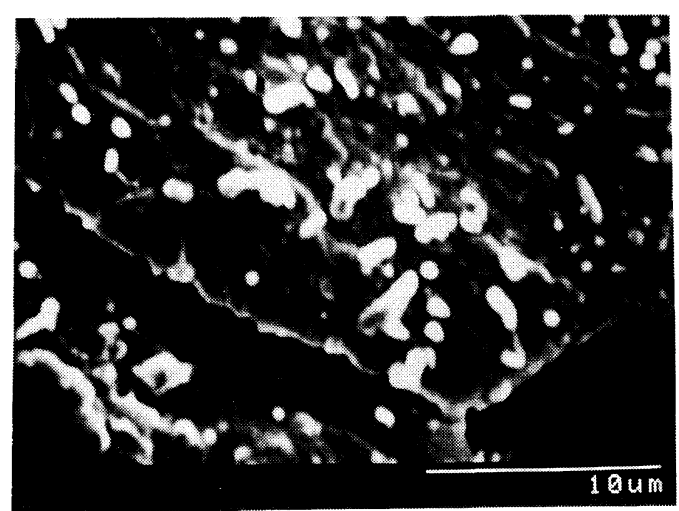

e

Figure 8.

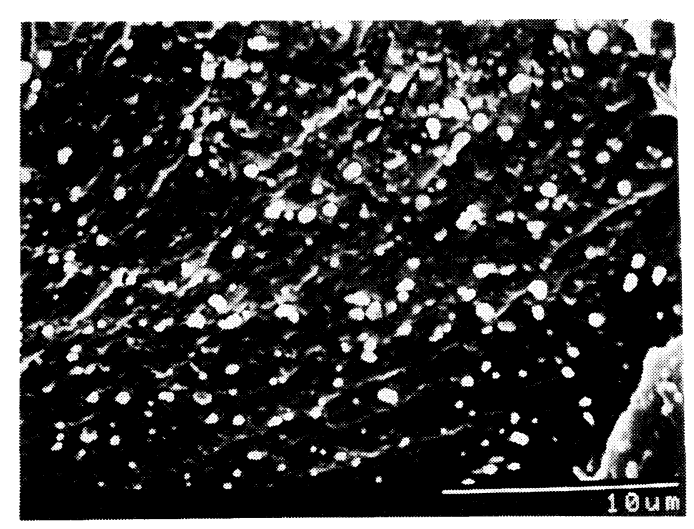

f

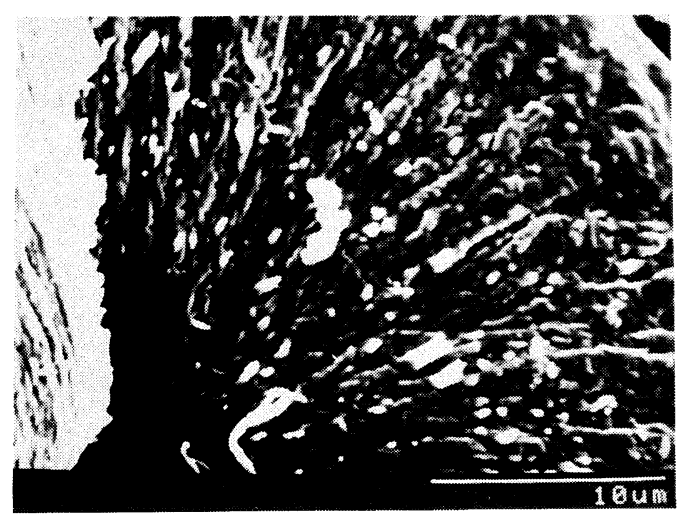

g

Figure 8. Scanning electron micrographs of LCP/PC $(5: 95)$ blend fibers for a draw ratio of 1 (a) fractured surface, (b) the residue following extraction, (c) tensile fracture; draw ratio of 3 (d) fractured surface, (e) tensile fracture; draw ratio of 8 (f) fractured surface, (g) tensile fracture.

of LCP show clearly higher mechanical properties in fiber axis than spheres. ${ }^{4,7)}$ The effects of the draw ratio on fibril formation are shown in Figure 9(c)-(f). Diameters of fibrils of LCP decrease with increasing draw ratio. The fibrils are oriented in the flow direction and have a large aspect ratio of a few hundred. Tensile fractures for a draw ratio of 3 and 8 (Figure 9(a), (c), (e)) show that largely elongated fibrils of LCP are scattered throughout the matrix and nearly parallel the plane of the surface. All 


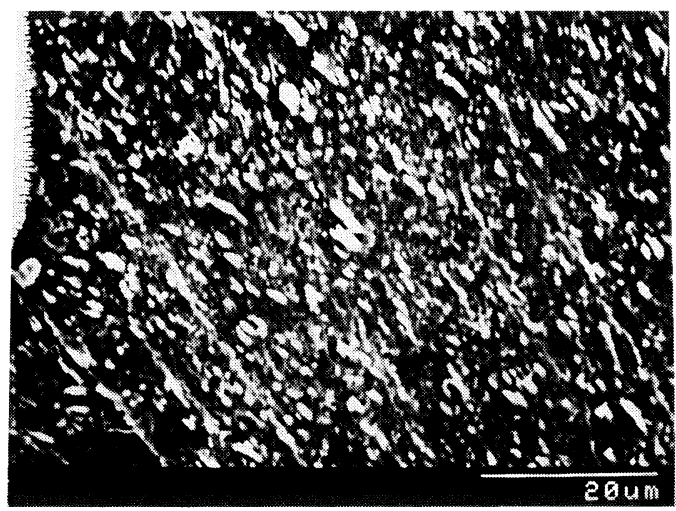

a

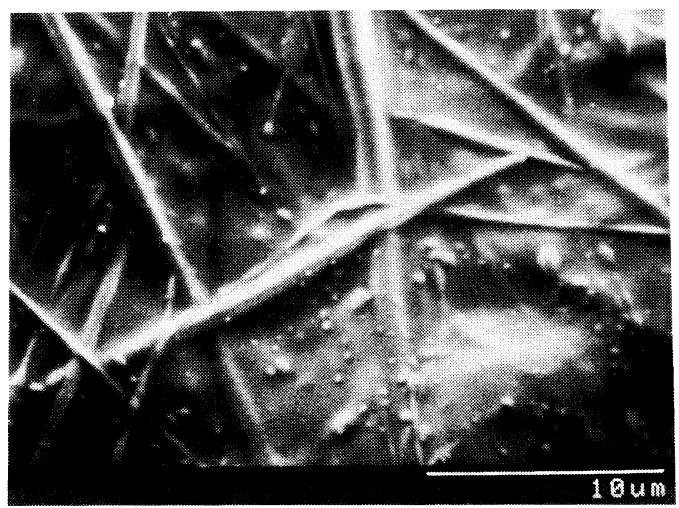

b

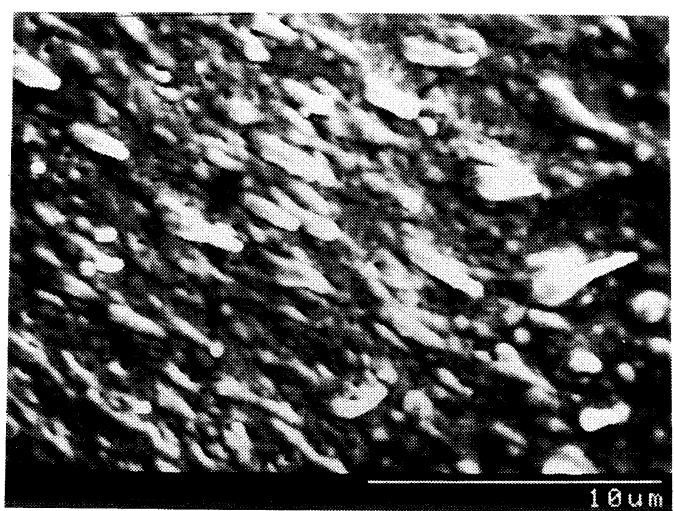

C

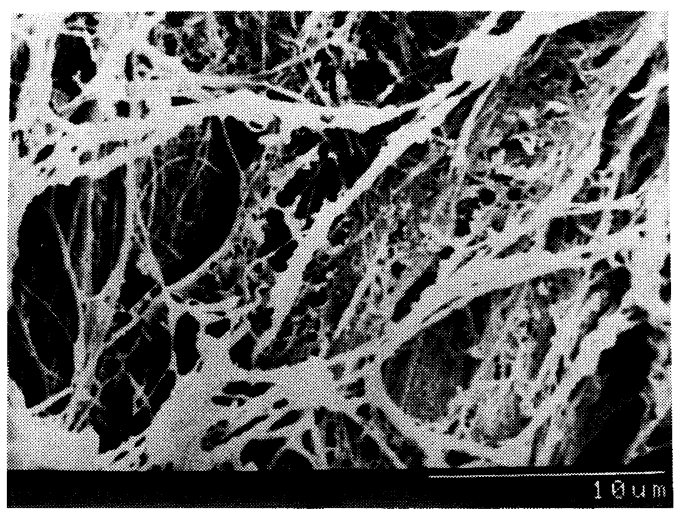

d

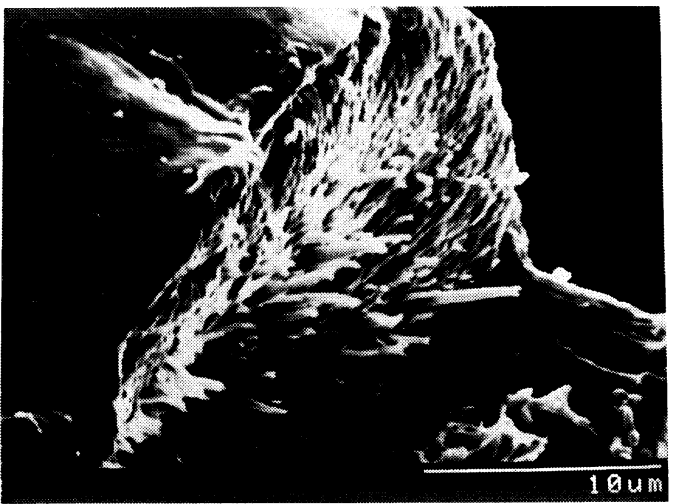

e

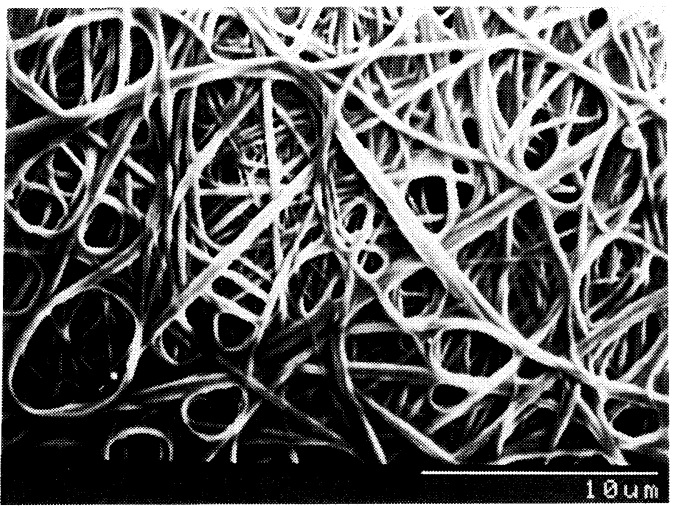

f

Figure 9. Scanning electron micrographs of LCP/PC (10:90) blend fibers for a draw ratio of 1 (a) tensile fracture, (b) the residue after extraction; a draw ratio of 3 (c) tensile fracture, (d) the residue after extraction; a draw ratio of 8 (e) tensile fracture, (f) the residue after extraction. 


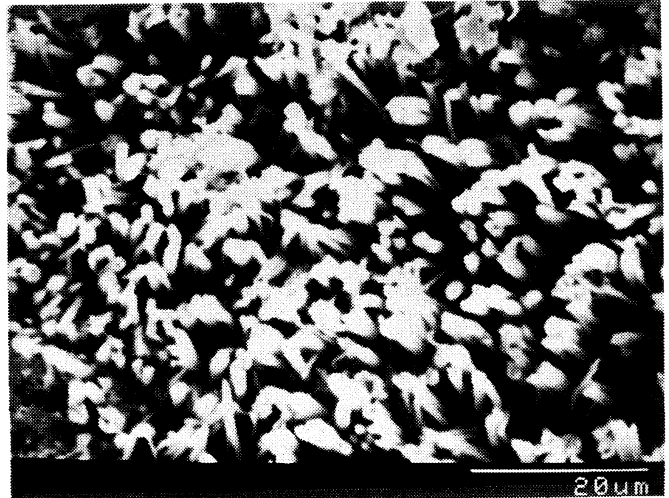

a

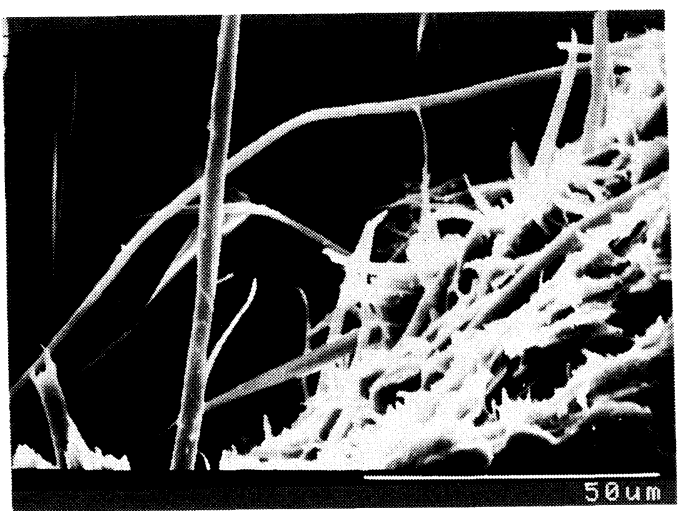

b

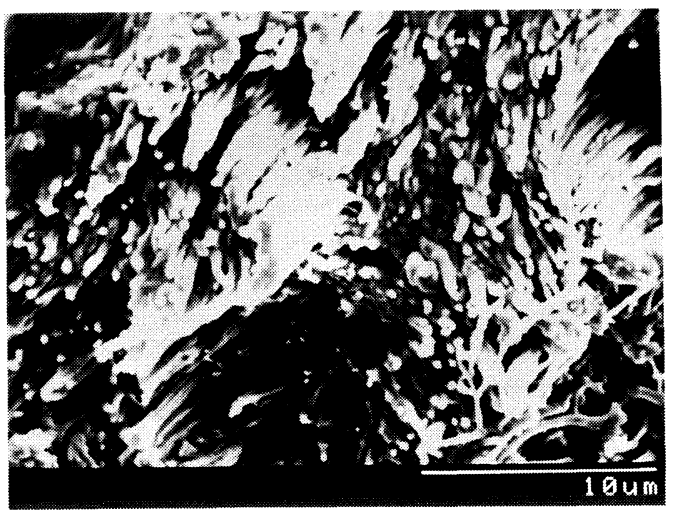

C

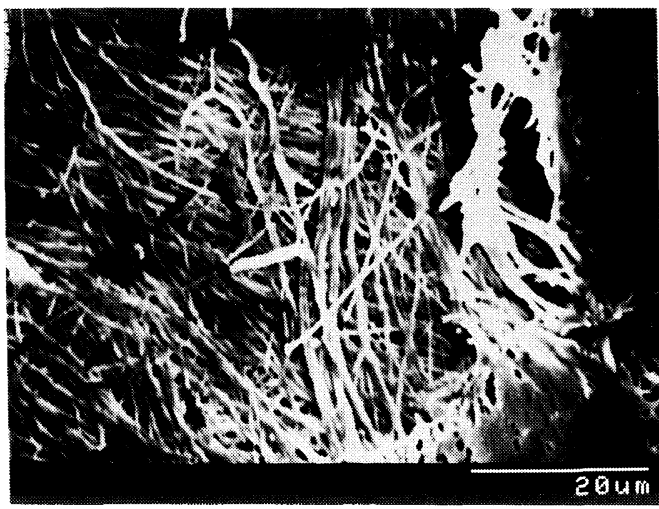

d

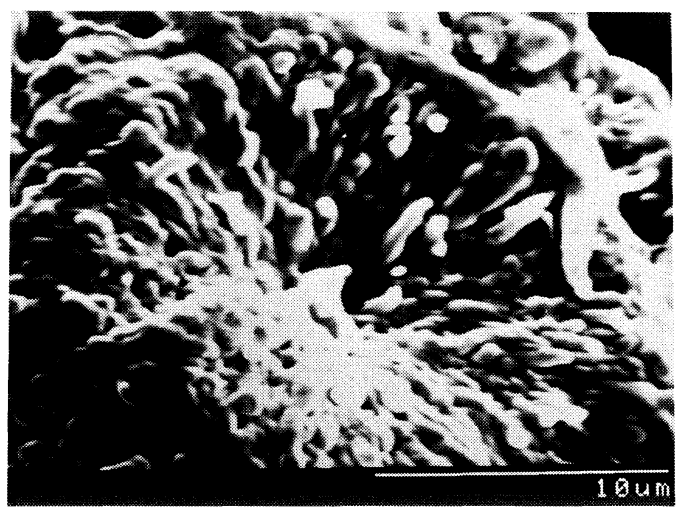

e

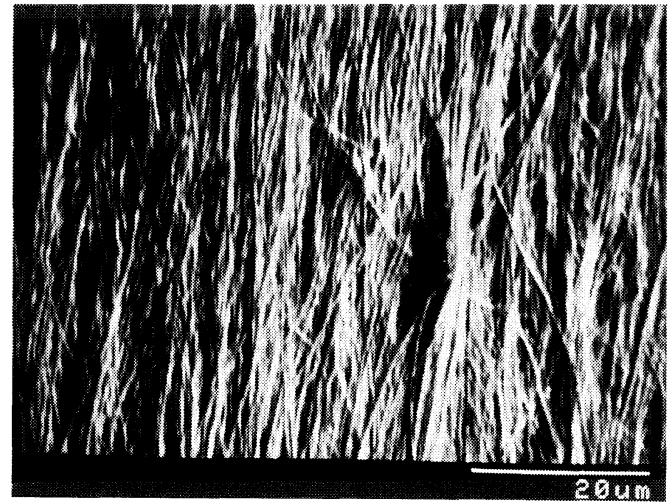

f

Figure 10. Scanning electron micrographs of LCP/PC $(30: 70)$ blend fibers for a draw ratio of 1 (a) tensile fracture, (b) the residue after extraction; a draw ratio of 3 (c) tensile fracture, (d) the residue after extraction; a draw ratio of 8 (e) tensile fracture, (f) the residue after extraction. 

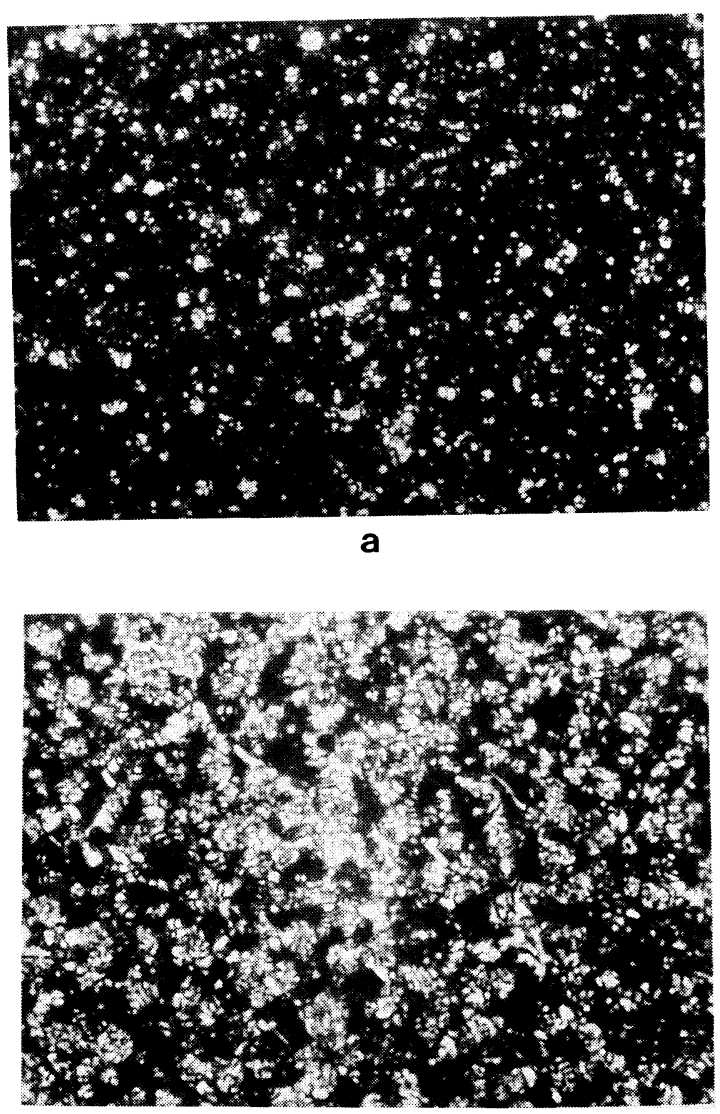

b

Figure 11. Polarized optical micrographs of LCP/PC blend at $280^{\circ} \mathrm{C}$ : (a) LCP/PC $(10: 90)$; (b) LCP/PC $(30: 70) .(320 \times)$

the fibrils are broken by tensile stress during tensile fracture. These results reveal that the fibrils of LCP have an extremely high aspect ratio. They are matched with the micrographs of etched surfaces in Figure 9(b), (d), and (f).

Figure 10 shows the morphology of the blend with $30 \mathrm{wt} \%$ of LCP for various draw ratios. Figure 10(a), (c), and (e) show tensile fractured surfaces for draw ratios of 1,3 , and 8 , respectively. Microfibrils are well oriented in the flow direction and fractured during the tensile test. Thus the adhesion between two phases is so good that the aspect ratio of a microfibril becomes very large. ${ }^{7}$ The diameter of a microfibril decreases with increase in draw ratio. As shown in Figure 10(b), (d), (f), the diameter is $1-6 \mu \mathrm{m}$ for a draw ratio of 1 , $0.1-1.5 \mu \mathrm{m}$ for a draw ratio of 3 and less than $0.6 \mu \mathrm{m}$ for a draw ratio of 8 . The aspect ratio of microfibril for the draw ratio of 8 may be larger than one thousand. This extremely high aspect ratio explains why the blend has three times the strength at the break and modulus than pure PC at a draw ratio of 8 .

Micrographs for the bulk state of the blend investigated using a cross-polarizing microscope are shown in Figure 11. The blend with $10 \mathrm{wt} \%$ of LCP has some spherical domains connected to each other (Figure 11(a)) but the blend with $30 \mathrm{wt} \%$ of LCP has no separated domains any more (Figure 11(b)). The latter has finer microfibrils in the flow direction than the former when Figures 9(f) and 10(f) are compared. This comparison indicates that LCP domains form easily microfibrils in the flow direction in the matrix by a shear or extensional flow at a certain blend ratio. We may conclude that the fibrillar formation of LCP in the matrix and interfacial adhesion between two polymers are very important factors for the improvement of mechanical properties.

\section{REFERENCES}

1. A. Cifferi, W. R. Krigbaum, and R. B. Meyer, "Polymer Liquid Crystal," Academic Press, New York, London, 1982.

2. Y. Ide and Z. Ophir, Polym. Eng. Sci., 23, 261 (1983).

3. G. W. Calundam and M. Jaffe, "Anisotropic Polymers, Their Synthesis and Properties," Proceedings of the Robert A. Welch Conference on Chemical Research, XXVI, Synthetic Polymers, 1982.

4. M. Takayanagi and T. Ogata, J. Macromol. Sci.Phys., B17, 591 (1980).

5. M. Takayanagi and K. Goto, J. Appl. Polym. Sci., 29, 2547 (1984).

6. F. N. Cogswell, B. P. Griffin, and J. B. Rose, U.S. Patent 4386174 (1983).

7. G. Kiss, Polym. Eng. Sci., 27, 410 (1987).

8. A. Siegman, A. Dagan, and S. Kenig, Polymer, 26, 1325 (1985).

9. S. H. Jung and S. C. Kim, Polym. J., 20, 73 (1988). 
10. B. Y. Shin and I. J. Chung, Polym. Eng. Sci., Submitted.

11. S. Middleman, "Fundamentals of Polymer Processing," McGraw-Hill, New York, N.Y., 1977.

12. S. Antoun, R. W. Lenz, and J.-I. Jin, J. Polym. Sci., Polym. Chem. Ed., 19, 1901 (1981).

13. G. Chen and R. W. Lenz, J. Polym. Sci., Polym. Chem. Ed., 22, 3189 (1984).
14. D. Demus and L. Richter, "Textures of Liquid Crystals," Verlag Chemie, Weinheim, 1978.

15. H. Muramatsu and W. R. Krigbaum, J. Polym. Sci., B: Polym. Phys., 25, 2303 (1987).

16. L. C. Sawyer and M. Jaffe, J. Mater. Sci., 21, 1897 (1986).

17. K. G. Blizard and D. G. Baird, Polym. Eng. Sci., 27, 653 (1987). 